
\title{
25 Research Soure \\ High-power radiofrequency ablation guided by ablation index for pulmonary vein isolation
}

\section{xuefeng zhu}

Qindao University Medical College Affiliated Yantai Yuhuangding Hospital https://orcid.org/00000002-5922-5189

\section{chunxiao wang}

Qindao University Medical College Affiliated Yantai Yuhuangding Hospital

jianping li ( $\sim$ lijianpingyt@qq.com )

wenjing li

Qindao University Medical College Affiliated Yantai Yuhuangding Hospital hongxia chu

Qindao University Medical College Affiliated Yantai Yuhuangding Hospital huihui zhou

Qindao University Medical College Affiliated Yantai Yuhuangding Hospital

\section{Technical advance}

Keywords: Atrial Fibrillation, Ablation Index, Pulmonary Vein Isolation, High-power

Posted Date: July 6th, 2020

DOl: https://doi.org/10.21203/rs.3.rs-21367/v2

License: (c) (1) This work is licensed under a Creative Commons Attribution 4.0 International License. Read Full License 


\section{Abstract}

Background: Proposed to facilitate pulmonary vein isolation (PVI), high-power ablation may cause extracardiac damage. This study evaluated the safety and efficacy of ablation index (Al) guided high-power ablation first in an animal model and subsequently in a clinical study.

Methods: Outcomes of radiofrequency (RF) applications were compared in a swine ventricular endocardial model ( $n=10$ each for 50W, 40W and 30W; $A l=500$ ), and in 100 consecutive patients with paroxysmal AF undergoing PVI (40W [last $n=50$ ] vs. $30 \mathrm{~W}$ [first $n=50]$; target $A \mathrm{I}=400 / 500$ on posterior/anterior wall, respectively). Acute PV reconnection was assessed post adenosine administration 20 minutes after ablation.

Results: In swine ventricular endocardial RF applications, use of $50 \mathrm{~W}$ and $40 \mathrm{~W}$ vs. $30 \mathrm{~W}$ was associated with greater tissue lesion depth $(5.06 \pm 0.16$ and $4.38 \pm 0.13 \mathrm{~mm}$ vs. $3.95 \pm 0.16 \mathrm{~mm} ; P<0.001)$ and smaller lesion maximum diameter $(7.81 \pm 0.15$ and $8.42 \pm 0.18 \mathrm{~mm}$ vs. $9.08 \pm 0.15 \mathrm{~mm} ; P<0.001)$. Tissue necrosis caused by $50 \mathrm{~W}$ vs. $40 \mathrm{~W}$ and $30 \mathrm{~W}$ was the deepest and largest $(3.15 \pm 0.18 \mathrm{~mm}$ vs. $2.71 \pm 0.17$ and $2.42 \pm 0.13 \mathrm{~mm}$; and $5.58 \pm 0.18 \mathrm{~mm}$ vs. $5.18 \pm 0.16$ and $3.94 \pm 0.17 \mathrm{~mm}$; respectively; $P<0.001)$. In $P V I$, use of $40 \mathrm{~W}$ vs. $30 \mathrm{~W}$ was associated with shorter procedure time $(56.54 \pm 1.81 \mathrm{~min}$ vs. $76.55 \pm 2.34 \mathrm{~min} ; \mathrm{p}<0.001)$ and ablation time (35.85 $\pm 14.87 \mathrm{~min}$ vs. $51.01 \pm 17.99 \mathrm{~min} ; \mathrm{p}<0.001)$; lower RF energy per point (909.02 $\pm 354.57 \mathrm{~J}$ vs. $1045 \pm 376.60 \mathrm{~J} ; \mathrm{p}<0.001)$; higher first-pass $\mathrm{PVI}(87 \%$ vs. $72 \%$; $P<0.01)$; lower acute PV reconnection ( $22 \%$ vs. $41 \% ; \mathrm{P}<0.01$ ); no complications in either group; and similar sinus rhythm maintenance at 12 months ( $92 \%$ vs. $84 \% ; P=0.22)$.

Conclusions: Al-guided high-power (40W) vs. conventional (30W) PVI was related to a reduced time for procedure and was considered safe, with diminished acute PV reconnection.

\section{Background}

Ablation through $\mathrm{RF}$ is popularly used in the treating patients with atrial fibrillation (AF) via transmural, continuous, and lasting lesion formation with PVI. Despite optimization of RF current transfer, RF energy transfer duration, stability of catheter and tissue in contact with catheter (1),PV reconnection occurs acutely after $\mathrm{PVI}$, at three months and at $22 \%$ and $15 \%$ frequencies, respectively $(2,3)$, mainly secondary to reversible damage, partial thickness and/or incomplete ablation(4-6). Intense power RF energy delivery, although, for a shorter length of time, could curtail the negative effects of the instability of catheter, that are inherent, leading to edema in tissue, and possibly enhance the lesion to lesion consistency by altering the link between resistive heating and conductive heating, allowing permanent tissue damage due to immediate heating while reducing the impact of heating due to conduction and as a consequence reduced damage to adjoining structures. To this end, shorter duration $50 \mathrm{~W}$ lesions have been associated with more effective long-term outcomes with no enhancement in complications rates(7). Higher intensity ablation constantly resulted in procedures of lesser duration, lesser dose of fluoroscopy, as well as declined delivery of gross RF energy Higher-power ablation consistently resulted in procedures of lesser 
duration, lesser dose of fluoroscopy, as well as declined delivery of total RF energy (8-9). In recent animal studies, $50 \mathrm{~W}$ ablation for 5 seconds was superior to lower-power, longer-duration ablation for lesion creation with lower complication rates $(10,11)$. A study conducted recently pointed out that by using contact catheters that are force-sensing and point-by-point ablation, 2-year freedom from paroxysmal and for persistent AF after one procedure was $86 \%$ and $72 \%$, respectively; per point, the average delivery time of the $50 \mathrm{~W}$ energy was only $11.2 \pm 3.7$ seconds, and $895 \pm 258$ seconds was the total duration of the delivery of RF energy (12). Many centers currently perform RF ablation using 25-35W power for 30-60 seconds at each point $(13,14)$. In the present 2-tiered study, we first tested in a swine model the effect of different power output on lesion creation at the ventricular level and compared lesion dimensions for the same Al value. A clinical study then assessed whether Al guided high-power ablation relative to Al guided standard power ablation is relevant for PVI in cases of paroxysmal AF.

\section{Methods}

The present study was divided into 2 successive parts. An animal study provided efficacy and safety data, which oriented the clinical study for the choice of RF duration. The 2 parts followed the same technical principles for clinical research.

Animal study

Swine hearts were obtained from an approved vendor (Shandong Animal Experiment Center) and studied at a laboratory of Yantai Yuhuangding Hospital. After pericardium excision, hearts were kept in a tissue bath with sodium chloride solution circulating at $0.9 \%$ at a consistent temperature of $37{ }^{\circ} \mathrm{C}$, and individual RF procedures were conducted at the endocardial aspect of the ventricles. RF ablation was conducted with a 3.5-mm-tip contact catheter that was force sensing and open irrigated (Thermo-Cool Smart Touch (ST), Biosense Webster, South Diamond Bar, CA). A steady Contact Force (CF) of $10 \mathrm{~g}$ was maintained by the operator who proceeded with the energy delivery after positioning the catheter perpendicular to the left ventricular tissue. For the same Al of 500, power output was $30 \mathrm{~W}$ for the control lesions and 40 Wand 50W for the study lesions, respectively, at ten ablation points. Ablation sites were $>10 \mathrm{~mm}$ apart to avoid any lesion overlap and to facilitate histopathologic evaluation. Lesions and necrotic areas were then divided into two perpendicular planes for the calculation of depth and maximum possible internal width. After proper fixation in $10 \%$ natural buffered formalin, hearts were trimmed to isolate all ablation sites, which were processed and embedded in paraffin. All paraffin blocks were subjected to microtome dissection twice serially at $5 \mu \mathrm{m}$, before being stained with hematoxylin and eosin for histopathologic analysis. The institutional Animal Research Ethics Committee approved animal handling procedures (2017.203).

\section{Clinical study}

\section{Patient population}


Subjects consisted of symptomatic patients who had consecutive paroxysmal AF undergoing initial point-by-point RF ablation at Yantai Yuhuangding Hospital (Yantai, China) from April 2018 to February 2019. The first 50 patients (control group) were treated with standard power $(30 \mathrm{~W}$ ), whereas the last 50 patients (study group) were treated with high-power (40 w). Study exclusion criteria were left atrium (LA) thrombus, ages less than eighteen years, prior AF ablation, ejection fraction of less than $35 \%$ of the left ventricle, severe coronary artery disease (CAD) or valvular disease, thyrotoxicosis, and a greater than 60 $\mathrm{mm}$ diameter of LA. For the ablation procedure, informed and written consent was obtained from all patients. The current study's protocol was approved by the Yantai Yuhuangding Hospital (Yantai, China) Ethics Committee (2017.203).

\section{Ablation protocol}

We have already elaborated the periprocedural anticoagulation protocols earlier(15). The procedure was performed under local anesthesia consisting of administration of lidocaine to the groin and left subclavian region, with the analgesic (fentanyl). The procedure is performed by a same independent skilled operator. The CARTO3 system (Biosense, Webster, Diamond Bar, CA) was used in all cases for 3D mapping. Three catheters were inserted: (1) a 6F decapolar catheter (Biosense Webster, Diamond Bar, CA) was placed into the coronary sinus ; (2) a multipolar mapping catheter (pentaray, Biosense Webster, Diamond Bar, CA) to create atrial anatomy shell; and (3) a 3.5-mm-tipped contact catheter that is force sensing and open irrigated (ST, Biosense Webster, South Diamond Bar, CA). Following a dual trans-septal puncture, 2 SL1 sheaths were introduced into the LA, a sheath for the Pentaray catheter (multipolar mapping catheter) and the other sheath for the CARTO ablation catheter. After creating an anatomical CARTO map of the LA, the borders of all four PVs were marked on the CARTO map. Next, all 4 PVs underwent encirclement by point-by-point RF applications (Target Al was 400 for the posterior segment, and 500 elsewhere) and other ablations as clinically indicated (Figure. 1). RF applications were conducted with power-control mode, temperature maintained at $45^{\circ} \mathrm{C}$, and saline irrigation ( 17 to 30 $\mathrm{mL} / \mathrm{min}$ ). Ablation was made targeting with a $\mathrm{CF}$ of $10-20 \mathrm{~g}$. Where $\mathrm{CF}$ was regularly less than $5 \mathrm{~g}$ or greater than $40 \mathrm{~g}$, ablation was paused, and adjustment of catheter position and orientation was undertaken as required. The operator was alerted with a flashing screen visual warning if the CF exceeded $30 \mathrm{~g}$. PVI was the endpoint of the procedure. Blockage of entrance was determined by the lack of PV potentials recorded with the tissue proximity instruction (TPI) of pentaray catheter (16). Blockage of exit was illustrated as the failure to capture the LA while pacing with the TPI of pentaray catheter within the antrum carina included (17). A waiting time of twenty minutes was noticed in both the groups subsequent to the $\mathrm{PVI}$, following which an administration of eighteen $\mathrm{mg}$ of adenosine was initiated with the pentaray in place to record PV reconnection. In the case of repetitive PV reconnection, RF ablation was performed to ensure isolation. However, in the case of transient reconnection, ablation was made and adenosine was repeatedly administered to ensure that there was no reconnection possibility. The Al Software Module (Biosense Webster Inc) was utilized for identification of Automatic lesion tagging (VISITAG). Ablation was performed with ST catheters in a controlled $40 \mathrm{~W}$ power mode in the study group and a controlled power mode of $30 \mathrm{~W}$ in the control group. CARTO was used with the "Distance Ruler" function; Taking the center of the last VISITAG, there is a continuous measurement of distance with 
changes being recorded in real time (Figure 1). At the commencement of an ablation lesion, the distance was maintained at less than $6 \mathrm{~mm}$. The radius of the VISITAGs were such that $3 \mathrm{~mm}$ ablation lesions were displayed and therefore VISITAGs of less than $6 \mathrm{~mm}$ could be seen to overlap (Figure. 1). Gaps, if any, between VIDITAGs were looked for subsequent to the completion of the circumferential line of ablation, making the geometry transparent, indicating that the result would be gaps that are greater than $6 \mathrm{~mm}$. An ablation lesion was used to fill gaps, if any were noticed. The operator's discretion prevailed whether to redo a lesion, in case there were VISITAGs that were not red (meaning the Al target was not met). In case the PV was not isolated after the circumferential line of ablation was completed, more ablation was done under the guidance of the pentaray catheter either with in the line of ablation or on it where the signal existed. In the intravenous ridge between PV, ablation was not conducted, unless PVI could not be achieved otherwise. First-pass antral isolation designated exit block obtained after initial anatomic encirclement.

\section{Analysis and Collection of Data}

Gender, CHADS2 and CHA2DS2-VASC scores, age, Body Mass Index (BMI), size of the LA, history of transient ischemic attacks (TIA) or strokes, existence of hypertension, diabetes, CAD, cardiomyopathy, and obstructive sleep apnea were recorded for each patient. We calculated the time for procedure per ablation, total RF times, and CF. Reporting of complications was per procedure. Steam pops, phrenic nerve paralysis, strokes occurring from 48 hours to 30 days and strokes occurring within 48 hours, death, incidence of pericardial tamponade, strokes occurring within 48 hours and, PV stenosis requiring intervention, atrioesophageal fistulas, and catheter char were the complications that were studied. The first ablation point to $\mathrm{PVI}$, not including additional ablation beyond PVI constituted the procedure time. The RF time was defined as the time for which RF energy was used. If there were no AF, atrial flutter, or tachycardia lasting more than 30s off antiarrhythmic drugs after a 3-month blanking period, then that constituted a successful ablation procedure.

\section{Post procedure Follow-up}

All patients were discharged home within 48 to 72 hours. Vitamin $\mathrm{K}$ antagonists or direct oral anticoagulants were prescribed for at least 2 months (subsequent strategy depending on the CHA2DS2VASc score). At the clinic, patients were given an ECG scan within 24 hours, and then subsequently at the end of three and nine months. Holter monitoring was performed at six months and twelve months and beyond as per the symptoms. Recurrence was defined by any documented episode of AF or atrial tachycardia lasting $>30$ s.

\section{Statistical analysis}

For each part of the study, the variables were presented as mean \pm Standard Deviation or percentages, as deemed fit. Continuous and categorical data were compared with the Student $t$ test (two-tailed) and the $\chi 2$ test (or Fisher exact test in case of small sample), respectively. $P<0.05$ was taken as statistically significant. 


\section{Results}

\section{Animal Study}

Table 1 shows a comparison of lesions and necrosis in control (30W) and study (40 W, 50W) swine hearts for a total of $30 \mathrm{RF}$ applications. By visual inspection, $50 \mathrm{~W}$ use was associated with shallower lesions; and increasing RF power and shortening RF duration yielded greater maximum diameter (green line) and larger and deeper tissue necrosis area (red line) and nuclear pyknosis by histopathology (Figure 2).

\section{Clinical study}

Hundred successive patients with paroxysmal AF were evenly distributed to control group (first 50 patients) and study group (last 50 patients); their baseline clinical characteristics are summarized in Table 2.A total of $8726 \mathrm{RF}$ lesions were administered to these 100 patients, and procedural data are compiled in Table 3. Figure 3 shows the spread of lesions by ranges of CF $(3.74 \%,<5 \mathrm{~g} ; 86.48 \%, 5-25 \mathrm{~g}$; $2 \%,>25 \mathrm{~g})$. The study vs. control group had shorter total procedure time $(56.54 \pm 1.81$ vs $76.55 \pm 2.34$ minutes, $p<0.001)$, left and right encirclement procedure time $(25.83 \pm 1.12$ vs $37.92 \pm 1.24$ minutes, and $30.92 \pm 1.31$ vs $38.33 \pm 3.06$ minutes; both $p<0.001)$, total ablation time required for PVI $(35.85 \pm 14.87$ vs $51.01 \pm 17.99$ minutes $p<0.001)$, ablation time per point in different parts of $P V$ and total RF energy delivered per procedure ( $909.02 \pm 354.57$ vs. $1045 \pm 376.60 \mathrm{~J}, p<0.001$; Figure 4$)$. Figure 5 shows the energy delivery per point throughout PV. Isolation of first pass was more frequent in the study group (87\% vs. $72 \%, p<0.01)$, occurring in both left and right in $70 \%$ PVs $(35 / 50)$ of study patients vs. $42 \%(21 / 50)$ of controls $(p<0.001)$. The study vs. control group required fewer additional ablations on the intervenous ridge between the PVs to isolate them ( $8 \%$ [8/100] vs. $21 \%$ [21/100], respectively, $p<0.001)$, and had fewer acute PV reconnections (11\% [22/200] vs. $23 \%$ [46/200], $p<0.001)$.

At mean $1.04 \pm 0.62$ years follow-up, the percentage of patients free from AF or atrial tachycardia after one procedure was $92 \%(46 / 50)$ in the study group and $84 \%(42 / 50)$ in the control group $(p=0.22)$. There were no cases of PV stenosis, stroke, pericardial tamponade, TIA, atrial-esophageal fistulae, or death.

\section{Discussion}

The present two-tiered animal and clinical study yielded four major findings. First, in swine hearts, higher vs. lower power RF applications were more effective in creating larger and deeper necrosis yet shallower lesions, while lower power was associated with deeper lesions without basophilic changes in connective tissue. Second, in patients with paroxysmal AF, high-power ablation was associated with lesser duration procedures and lesser total RF energy delivery, especially on the left anterior wall. Third, Al, the novel marker incorporating time, power and contact force, reliably predicted the degree of necrosis in RF delivery. Fourth, higher power combined with Al increased PVI effectiveness with more frequent first-pass isolation, decreased acute reconnection, and favorable 12-month outcomes. 
Myocardial lesion creation starts at $45^{\circ} \mathrm{C}$, being partially reversible below $50^{\circ} \mathrm{C}$ (transient stunning), and definitive above $50^{\circ} \mathrm{C}$ (durable necrosis)(18). Delivery of RF energy to the tissue is a complicated interaction(1). Thermal injury induced by electrical current delivery with an irrigated-tip comprises resistive and the conductive phases. Resistive heating is a relation between the actual current supplied to the tissue, with the resistance of the RF generator which probably occurs relatively early in the RF application. By using lower resistance or greater RF power, better resistive heating can be achieved. For instance, with standard power $(25-30 \mathrm{~W})$, temperature already rises above $50^{\circ} \mathrm{C}$, but tissue necrosis is confined to the first 1 to $1.5 \mathrm{~mm}$ from the ablation catheter tip (19). Conductive heating, which is a secondary passive heating of deeper tissue increases with the period of RF applications. An electrically silent scar is obtained when the tissue is heated to $50^{\circ} \mathrm{C}$ or higher for several seconds thereby obtaining irreversible coagulation necrosis. Force sensing and stability monitoring have considerably facilitated the reproducibility of heat transmission to the tissue $(20,21)$. The balance between power and duration parameters, respectively involved in resistive and conductive heating, therefore has a growing influence on lesion creation. By increasing resistive heating size, high-power (40-50W) may theoretically favor the creation of durable lesions (temperature above $50^{\circ} \mathrm{C}$ ) whose dimensions might be particularly suitable for PVI because antral thickness is consistently below $4 \mathrm{~mm}$ (22).

\section{Animal experiments}

In the present study in swine left ventricular myocardium, $50 \mathrm{~W}$ power ablations for short durations at $10 \mathrm{~g}$ of CF created larger and deeper necrosis than that observed with $40 \mathrm{~W}$ and $30 \mathrm{~W}$ of power; however, use of $30 \mathrm{~W}$ resulted in deeper lesions but without basophilic changes which might render them more susceptible to tissue recovery. Higher power, shorter duration applications were more effective in creating larger and deeper necrosis yet shallower lesions may be due to reduced temperature rise in deeper tissue relative to standard lesions. However, the area of tissue necrosis near the surface of the ablation catheter tip is larger because it is more dependent on resistive heating, which is proportional to power. The larger diameter of necrosis in study group may lead to complete encirclement of PVs, due to more effective contiguity with adjacent necrosis. At the same time, it was found that higher power (50W) ablation may lead to more complete cell necrosis. However, nuclear pyknosis was observed only more superficially with low-power ablation, and only cell edema was present in the deep part, which may lead to cell reactivation and consequent acute and late $\mathrm{PV}$ reconnection and $\mathrm{AF}$ recurrence.

\section{Clinical research}

\section{Procedural time}

In the present study, high-power ablation was associated with shorter procedural duration due to shorter time required for lesion creation, more first-pass PVI, and fewer acute PV reconnections. Nilsson et al(23) reported that ablation with $45 \mathrm{~W}$ for 20 seconds vs. 30W for 120 seconds was associated with shorter PVI period, mean fluoroscopy time, radiation dose, and total time of RF application. In ventricles from freshly killed pigs, Ahmed et al(11) demonstrated that for $20 \mathrm{~g}$ of CF, the time required to generate a 4-mm deep lesion decreased from about 20 s at $20 \mathrm{~W}$ to $6-7 \mathrm{~s}$ for $50 \mathrm{~W}$. In the present study, under the same pressure, 
the ablation time per point of the LA posterior wall in the high-power group was 8-9s shorter than that in the control group, and 10-13s shorter for the LA anterior wall. Because catheter instability in a constantly beating heart may also account for the difficulty to transmit heat to the tissue, RF application time shortening probably optimizes lesion creation by increasing the likelihood of catheter stability throughout the entire RF application, particularly for ablation of the LA anterior wall by the appendage ridge on the left artery. The significantly smaller pressure of $<10 \mathrm{~g}(60 \%)$ used for the LA anterior wall than for the other three surfaces helps avoid catheter slippage $\mathbb{F}$ Figure 6囚. However, low power use requires longer time which increases catheter slippage, and the additional time spent adjusting the catheter may cause discontinuous ablation tissue edema, lower first-pass PVI rate, and increased risk of acute PV reconnections. In the present study, ablation time of the left anterior wall was longer than that of other parts of the LA in both study and control groups $\varangle$ Figure 7区; however, it showed lesser time in the study when compared to the control group likely secondary to shorter time required to adjust the catheter or the ineffective point of ablation(procedure time minus total ablation time).

\section{Al value}

Al, a novel marker in a weighted formula utilizing time, contact force and power in a weighted formula. The use of contact force targets and ablation output markers such as Force-Time Integral diminishes recurrence and complication rates in cohorts of patients with AF undergoing PVI $(3,24,25)$. Single-center studies on Al-guided ablation have demonstrated a very high first pass PVI rates of $97 \%$ to $98 \%$ and $2 \%$ to $6 \%$ PV Reconnection rates, which are very low $(25,26)$. In the present study on Al-guided high-power ablation, numbers of first-pass PVI were elevated at $87 \%$ albeit lesser when compared to earlier reports. Equivalently, when compared to controls the numbers for acute PV reconnection were lower (11\%). The targets of Al were arbitrary, with ranges for posterior walls at 380 to 400 while for other areas it was 550 . ST catheters delivering high power was the novel combination used in this study. With reference to this, the Al target of 400 for posterior wall and 500 for other places has contributed to higher First Pass PVI rates and lower acute PV reconnection rates.

\section{First-pass PVI}

In Al guided centered evaluation of high power ablation, Dhillon G (27) reported more frequent first-pass $\mathrm{PVI}$. Leshem $\mathrm{E}$ (28)compared ablation using $90 \mathrm{~W}$ for a duration of four seconds to $25 \mathrm{~W}$ for a duration of twenty seconds. The $90 \mathrm{~W}$ four second ablation resulted in lesions with full thickness and no gaps in all cases, while the 25W 20 second ablation yielded partially thick lesions with several gaps between the lesions. At 25W for a 20 second duration, "endocardial sparing" seemed to occur due to the catheter tip irrigation, which was perceived to be a scar creation failure since there was not enough resistive heating as a result of cooling due to irrigation, for the tissue to be destroyed. In the present animal study experiment, use of higher power was associated with larger maximum diameter and more thorough tissue necrosis. Greater size and better consistency of the created tissue necrosis may explain why high power increases procedure efficiency by ensuring more first-pass PVI and fewer reconnections at 20 minutes. 


\section{Acute PV reconnections}

An important requirement for the success of the procedure is the durability of PVl; Late as well as acute $\mathrm{PV}$ reconnection have been known to cause $\operatorname{AF}(29,5)$. In a study using an open irrigated-tip catheter, patients undergoing ablation at $50 \mathrm{~W}$ vs. $35 \mathrm{~W}$ had greater freedom from AF ( $82 \%$ vs. $66 \%$ ) (30). The concept of the "weakest link" indicating locations of reconnection was explained in the recent past by ElHaddad and colleague (31), who discovered that the absence of contiguous lesion sets and the insufficiency of lesion depth cause the sites of reconnection. Okamatsu $\mathrm{H}$, et al (32) demonstrated that Al-guided PVI, the high-powered RF application can shorten the time to complete PVI with a high rate of first-pass isolation and reduced acute PV reconnection. Consistent with other studies, the present one documented fewer acute PV reconnections in the high- vs. standard power group, and in an animal model, higher power caused more thorough tissue necrosis thereby precluding cell restoration and reducing acute $\mathrm{PV}$ connection.

\section{Complications}

By avoiding tissue damage caused by distant conductive heating, which becomes perceptible at later stages of longer duration RF applications, and providing solutions by way of shorter duration, but higher power RF energy delivery, where in tissue destruction happens at the earlier portion of the RF application . In porcine ventricles of freshly killed pigs, Goyal et al(11) demonstrated that to create a $4 \mathrm{~mm}$ deep ablation the time taken was twenty seconds at 20W, whereas at $5 \mathrm{~W}$ it was a mere 6-7 seconds, there by implying that collateral injury can very much be reduced by utilizing the higher power lesser duration RF applications approach. Bhaskaran et al(10) demonstrated that a 5 second procedure at $50 \mathrm{~W}$ achieved transmural lesions which were inherently safer than a 30 second procedure at $40 \mathrm{~W}$. While there was a $8 \%$ incidence of steam pops in a 30 second procedure at $40 \mathrm{~W}$, there were none in a 5 second procedure at $50 \mathrm{~W}$. Winkle et al(7) created a comparison between a 3 to 10 second $50 \mathrm{~W}$ short duration procedure using open tip irrigated catheters and a 25 to 40 second lower power application. There was no increase in complications and there were much greater incidence of freedom from AF long term, with shorter procedural and fluoroscopy times. Winkle(33) compared the incidences of complications at four experienced centers between AF ablations performed at $45 \mathrm{~W}$ to $50 \mathrm{~W}$ power intensity over 2 to 15 second durations per lesion, against reduced power $30 \mathrm{~W}$ procedures over 20 second durations, and concluded that ablations performed at $45 \mathrm{~W}$ to $50 \mathrm{~W}$ over short durations yielded results with very low complication rates. Our clinical results cannot provide definitive information (for example using esophageal temperature monitoring) on whether high-power, short-duration lesions were safer than low-power energy delivered for a longer time. However, our histological results confirmed shallower tissue lesions with highpower than low-power ablation, with shorter ablation time reflecting shorter time for catheter to attach to the atrial wall tissue, thus leading to higher safety. In addition, the extremely low complication rate may be reassuring for using $40 \mathrm{~W}$ in LA at short duration, and may encourage considering use of high power short time RF ablations to enjoy the benefit of reduced procedural time, fluoroscopy, and total RF energy delivery times, even on the posterior wall. 


\section{Limitations}

Despite this observational study demonstrating encouraging results, their robustness is limited by several factors. First, degree of esophageal injury during ablation is unclear because all patients were treated under local anesthesia and could not tolerate esophageal temperature monitoring, and no postoperative endoscopic examination was performed. Second, the relatively fixed Al values used may be insufficient or excessive for some patients, especially for thin women. Third, because ST were used instead of Smart Touch Surround Flow (STSF) catheter, there is a small amount of scab at the catheter tip during the 50W ablation inanimal study, for which, 50W was not selected for ablation in clinical research. Fourth, after a year, there was similar sinus rhythm maintenance rate after ablation with $30 \mathrm{~W}$ and $40 \mathrm{~W}$ which may because of the numbers in each group were probably too small to look at a real difference in these two techniques. However, use of 50W during ablation may further improve long-term prognosis.

\section{Conclusions}

In the present study of high-power ablation, use of guidance by Al, which provides a rational local endpoint allowing for a tailored short-duration radiofrequency application associated with optimized lesion metrics, translated into shorter procedural time and improved acute efficacy, without compromising safety profile and long-term outcomes relative to standard-power ablation.

\section{Declarations}

\section{Ethics approval and consent to participate}

All patients enrolled in the study signed informed consent documentation. All experimental procedures were conducted under the approval of the Clinical Experiment Ethics Committee of Yantai Yuhuangding Hospital. All clinical investigations were conducted according to the principles expressed in the Declaration of Helsinki.

\section{Consent for publication}

Not applicable

\section{Availability of data and materials}

The datasets generated during the current study are not publicly available yet, due to privacy concerns and ongoing additional research. Data can be made available for peer review on reasonable request through contacting the corresponding author.

\section{Competing interests}

The authors declare that they have no competing interests. 


\section{Funding}

No funding was received.

\section{Authors' contributions}

ZXF and LJP designed the study. ZXF ,WCX, LJP, CHX and ZHH performed the experiements. LWJ and $\mathrm{ZHH}$ analysed the data.ZXF and LWJ prepared the manuscript. All authors have seen and approved the final published version of this manuscript.

\section{Acknowledgements}

Not applicable

\section{Abbreviations}

$\mathrm{PVI}$ : pulmonary vein isolation ; Al : ablation index ; RF: radiofrequency ; AF: atrial fibrillation ; PV:pulmonary vein ; ST : Thermo-Cool Smart Touch ; CF : Contact Force ; BMI: Body Mass Index ; CHA2DS2-VASc: congestive heart failure, hypertension, age $\geq 75$ years, diabetes mellitus, prior stroke or transient ischemic attack or thromboembolism, vascular disease, age 65-74 years, sex category ; LA: left atrium ;CAD :coronary artery disease ;TIA: transient ischemic attacks; STSF: SmartTouch Surround Flow

\section{References}

1. Kumar S, Barbhaiya CR, Balindger S, et al. Better lesion creation and assessment during catheter ablation. J Atr Fibrillation.2015,8:62-73.

2. Ullah W, McLean A, Tayebjee MH, et al. Randomized trial comparing pulmonary vein isolation using the SmartTouch catheter with or without real-time contact force data. Heart Rhythm.,2016.13:17617.

3. Kautzner J, Neuzil P, Lambert H, et al. EFFICAS II: optimization of catheter contact force improves outcome of pulmonary vein isolation for paroxysmal atrial fibrillation. Europace.2015,17: 1229-1235.

4. Andrade JG, Monir G, Pollak SJ, et al. Pulmonary vein isolation using "contact force" ablation: the effect on dormant conduction and long-term freedom from recurrent atrial fibrillation-a prospective study. Heart Rhythm.2014,11:1919-24.

5. Anter E, Contreras-Valdes FM, Shvilkin A, Tschabrunn CM, Josephson ME. Acute pulmonary vein reconnection is a predictor of atrial fibrillation recurrence following pulmonary vein isolation. $J$ Interv Card Electrophysiol.2014,39:225-32.

6. Anter E, Tschabrunn CM, Contreras-Valdes FM, Buxton AE, Josephson ME. Radiofrequency ablation annotation algorithm reduces the incidence of linear gaps and reconnection after pulmonary vein isolation. Heart Rhythm.2014;11:783-90. 
7. Winkle RA, Mead RH, Engel G, Patrawala RA. Atrial fibrillation ablation: perpetual motion of open irrigated tip catheters at 50 watts is safe and improves outcomes. Pacing Clin Elecrophysiol.2011;34(5):531-9.

8. Kanj MH, Wazni O, Fahmy T, et al. Pulmonary vein antral isolation using an open irrigation ablation catheter for the treatment of atrial fibrillation. J Am Coll Cardiol.2007;49:1634-1641.

9. Nilsson B, Chen X, Pehrson S, Svendsen JH. The effectiveness of a high output/short duration radiofrequency current application technique in a segmental pulmonary vein isolation of atrial fibrillation. Europace.2006;8:962-965.

10. Bhaskaran A, Chik W, Pouliopoulos J, et al. Five seconds of $50 \mathrm{~W}$ radio frequency atrial ablations were transmural and safe: an in vitro mechanistic assessment and force-controlled in vivo validation. Europace.2016;19:874-880.

11. Ali-Ahmed, F.Goyal, V.Patel, M.Orelaru, F.Haines, D. E.Wong, W. S. High-power, low-flow, short-ablation duration-the key to avoid collateral injury? J Interv Card Electrophysiol.2019;55:9-16.

12. Winkle RA, Moskovitz R, Mead RH, et al. Atrial fibrillation ablation using very short duration $50 \mathrm{~W}$ ablations and contact force sensing catheters. J Interv Card Electrophysiol.2018;52:1-8.

13. Reddy VY, Shah D, Kautzner J, et al. The relationship between contact force and clinical outcome during radiofrequency catheter ablation of atrial fibrillation in the TOCCATA study. Heart Rhythm.2012;9:1789-1795.

14. Reddy VY, Dukkipati SR, Neuzil P, et al. Randomized, controlled trial of the safety and effectiveness of a contact force-sensing irrigated catheter for ablation of paroxysmal atrial fibrillation: results of the TactiCath Contact Force Ablation Catheter Study for Atrial Fibrillation (TOCCASTAR) study. Circulation.2015;132:907-915.

15. Winkle RA, Mead RH, Engel G, Kong MH, Patrawala PA. Periprocedural interrupted oral anticoagulation for atrial fibrillation ablation: comparison of aspirin, warfarin, dabigatran, and rivaroxaban. Europace. 2014;16(10):1443-9.

16. Calkins H, Hindricks G, Cappato R,et al. 2017 HRS/EHRA/ECAS/APHRS/SOLAECE expert consensus statement on catheter and surgical ablation of atrial fibrillation. Europace. 2018;20:e1-e160.

17. Pambrun $T$, Combes $S$, Sousa $P$, et al. Contact-force guided single-catheter approach for pulmonary vein isolation: feasibility, outcomes, and cost-effectiveness. Heart Rhythm.2017;14:331-338.

18. Nath S, Lynch C III, Whayne JG, Haines DE. Cellular electrophysiological effects of hyperthermia on isolated guinea pig papillary muscle. Implications for catheter ablation. Circulation. 1993;88(4 pt 1):1826-1831.

19. Wittkampf FH, Nakagawa H. RF catheter ablation: lessons on lesions. Pacing Clin Electrophysiol. 2006;29:1285-1297.

20. Marijon E, Fazaa S, Narayanan K, et al. Realtime contact force sensing for pulmonary vein isolation in the setting of paroxysmal atrial fibrillation: procedural and 1-year results. J Cardiovasc Electrophysiol. 2014;25:130-137. 
21. Zucchelli G, Sirico G, Rebellato L, et al. Contiguity between ablation lesions and strict catheter stability settings assessed by VISITAGTM module improve clinical outcomes of paroxysmal atrial fibrillation ablation- results from the VISITALY study. Circ J.2018; 82:974-982.

22. Ho SY. Sanchez-Quintana D.Cabrera, J A. Anderson R H. Anatomy of the left atrium: implications for radiofrequency ablation of atrial fibrillation. J Cardiovasc Electrophysiol. 1999;10:1525-1533.

23. Nilsson B, Chen X, Pehrson S, Svendsen JH. The effectiveness of a high output/short duration radiofrequency current application technique in segmental pulmonary vein isolation for atrial fibrillation.2006; Europace 8:962-965.

24. Das M, Loveday JJ, Wynn GJ, et al: Ablation index, a novel marker of ablation lesion quality: Prediction of pulmonary vein reconnection at repeat electrophysiology study and regional differences in target values. Europace.2017;19:775-783.

25. 25. Taghji P, El Haddad M, Phlips T, et al: Evaluation of a Strategy Aiming to Enclose the Pulmonary Veins With Contiguous and Optimized Radiofrequency Lesions in Paroxysmal Atrial Fibrillation. JACC Clin Electrophysiol.2018;4(1):99-108.

26. Hussein A, Das M, Chaturvedi V, et al: Prospective use of Ablation Index targets improves clinical outcomes following ablation for atrial fibrillation. J Cardiovasc Electrophysiol.2017;28:1037-1047.

27. Dhillon G, Ahsan S, Honarbakhsh S, et al .

A multicentered evaluation of ablation at higher power guided by ablation index: Establishing ablation targets for pulmonary vein isolation. J Cardiovasc Electrophysiol Mar.2019;30(3):357-365.

28. Leshem E, Silberman I, Tschabrunn CM,et al. High-power and short-duration ablation for pulmonary vein isolation: biophysical characterization. JACC Clin Electrophysiol.2018;24:467-479.

29. 29. Efremidis M, Letsas K, Giannopoulos G, et al. Early pulmonary vein reconnection as a predictor of left atrial ablation outcomes for paroxysmal atrial fibrillation. Europace.2015;17 (5):741-6.

30. Kanj MH, Wazni O, Fahmy T, et al. Pulmonary vein antral isolation using an open irrigation ablation catheter for the treatment of atrial fibrillation. J Am Coll Cardiol.2007;49:1634-1641.

31. El Haddad M, Taghji P, Phlips T, et al. Determinants of Acute and Late Pulmonary Vein Reconnection in Contact Force-Guided Pulmonary Vein Isolation: Identifying the Weakest Link in the Ablation Chain. Circ Arrhythm Electrophysiol.2017; 10 (4).

32. Okamatsu, H;Koyama, J;Sakai, Y;et al.High-power application is associated with shorter procedure time and higher rate of first-pass pulmonary vein isolation in ablation index-guided atrial fibrillation ablation.J Cardiovasc Electrophysiol.2019;30(12):2751-2758.

33. 33. Winkle, R. A;Mohanty, S;Patrawala, R. A; et al. Low complication rates using high power (45-50 W) for short duration for atrial fibrillation ablations. Heart Rhythm.2019;16(2)165-169.

\section{Tables}

\section{Table 1. Swine Ventricular Lesion And Necrosis Characteristics}




\begin{tabular}{|l|l|l|l|l|}
\hline Variable & $50 \mathrm{w}$ & $40 \mathrm{w}$ & $30 \mathrm{w}$ & PValue \\
\hline $\begin{array}{l}\text { ablation time per } \\
\text { point, s* }\end{array}$ & $20.00 \pm 1.095$ & $27.78 \pm 9.72$ & $44.83 \pm 9.83$ & $<0.001$ \\
\hline $\begin{array}{l}\text { Ventricular lesion } \\
\text { impedance drop } \Omega^{*}\end{array}$ & $13.5 \pm 1.871$ & $9.11 \pm 1.537$ & $6.17 \pm 0.983$ & $<0.001$ \\
\hline $\begin{array}{l}\text { Energy delivery per } \\
\text { point, J* }\end{array}$ & $992.33 \pm 54.331$ & $1085.11 \pm 45.018$ & $1337.00 \pm 24.421$ & $<0.001$ \\
\hline $\begin{array}{l}\text { Ventricular tissue lesions } \\
\text { depth, mm* }\end{array}$ & $3.95 \pm 0.16$ & $4.38 \pm 0.13$ & $5.06 \pm 0.16$ & $<0.001$ \\
\hline $\begin{array}{l}\text { Ventricular tissue } \\
\text { necrosis depth, mm* }\end{array}$ & $3.15 \pm 0.18$ & $2.71 \pm 0.17$ & $2.42 \pm 0.13$ & $<0.001$ \\
\hline $\begin{array}{l}\text { Ventricular tissue lesions } \\
\text { width, mm* }\end{array}$ & $9.08 \pm 0.15$ & $8.42 \pm 0.18$ & $7.81 \pm 0.15$ & $<0.001$ \\
\hline $\begin{array}{l}\text { Ventricular tissue } \\
\text { necrosis width, mm* }\end{array}$ & $5.58 \pm 0.18$ & $5.18 \pm 0.16$ & $3.94 \pm 0.17$ & $<0.001$ \\
\hline
\end{tabular}

Values are mean \pm SD or $\mathrm{n}(\%)$

Table 2. Clinical Characteristics 


\begin{tabular}{|c|c|c|c|}
\hline Variable & $\begin{array}{l}\text { Study Group; } \\
\text { High-Power; } \\
\text { (50 Patients) }\end{array}$ & $\begin{array}{l}\text { Control Group; } \\
\text { Standard } \\
\text { Power; (50 } \\
\text { Patients) }\end{array}$ & $P$ Value \\
\hline Age, $\mathrm{y}^{*}$ & $64.4 \pm 9.45$ & $64.9 \pm 8.62$ & 0.862 \\
\hline Male, n (\%) & $34(68)$ & $32(64)$ & 0.673 \\
\hline LV ejection fraction, \% & $64.74 \pm 4.46$ & $61.9 \pm 5.40$ & 0.08 \\
\hline Left atrial size (mm) & $40.65 \pm 5.87$ & $42.85 \pm 3.10$ & 0.147 \\
\hline Hypertension, n (\%) & $22(44)$ & $26(52)$ & 0.423 \\
\hline Diabetes mellitus, $\mathrm{n}(\%)$ & $6(12)$ & $8(16)$ & 0.564 \\
\hline Body mass index & $21.27 \pm 1.88$ & $21.04 \pm 2.65$ & 0.749 \\
\hline Prior stroke/transient ischemic attackn (\%) & $8(16)$ & $10(20)$ & 0.603 \\
\hline Coronary artery disease $\mathrm{n}(\%)$ & $14(28)$ & $12(24)$ & 0.648 \\
\hline CHADS2 score & $2.1 \pm 0.64$ & $1.95 \pm 0.80$ & 0.504 \\
\hline CHA2DS2-VASC score & $3.4 \pm 1.14$ & $3.15 \pm 1.04$ & 0.474 \\
\hline Obstructive sleep apnea n (\%) & $6(12)$ & $7(14)$ & 0.766 \\
\hline Dilated cardiomyopathyn (\%) & $3(6)$ & $3(6)$ & 1 \\
\hline
\end{tabular}

Values are mean \pm SD or $\mathrm{n}(\%)$

Table 3. Procedural Characteristics 


\begin{tabular}{|c|c|c|c|}
\hline Variable & $\begin{array}{l}\text { Study Group; High } \\
\text { Power } 40 \mathrm{w} \square 50 \\
\text { Patients }\end{array}$ & $\begin{array}{l}\text { Control Group; } \\
\text { Standard } \\
\text { Power(30w); } 50 \\
\text { Patients }\end{array}$ & $\begin{array}{l}\mathrm{P} \\
\text { Value }\end{array}$ \\
\hline Procedure time, min & $56.54 \pm 1.81$ & $76.55 \pm 2.34$ & $<0.001$ \\
\hline $\begin{array}{l}\text { Right encirclement Procedure } \\
\text { time, } \\
\text { min }\end{array}$ & $30.92 \pm 1.31$ & $38.33 \pm 3.06$ & $<0.001$ \\
\hline $\begin{array}{l}\text { Left encirclement Procedure } \\
\text { time, min }\end{array}$ & $25.83 \pm 1.12$ & $37.92 \pm 1.24$ & $<0.001$ \\
\hline Right encirclement points $\square \mathrm{n}$ & $51.25 \pm 2.45$ & $49.08 \pm 3.58$ & 0.1 \\
\hline Left encirclement points $\square \mathrm{n}$ & $44.42 \pm 1.44$ & $45.00 \pm 1.91$ & 0.407 \\
\hline Total ablation time, min & $35.85 \pm 14.87$ & $51.01 \pm 17.99$ & $<0.001$ \\
\hline Contact-force, $\mathrm{g}^{*}$ & $12.07 \pm 5.34$ & $11.85 \pm 5.40$ & 0.523 \\
\hline $\begin{array}{l}\text { Ablation time per } \\
\text { point, s }\end{array}$ & $22.64 \pm 9.39$ & $32.56 \pm 11.48$ & $<0.001$ \\
\hline Energy delivery per point, J* & $909.02 \pm 354.57$ & $1045 \pm 376.60$ & $<0.001$ \\
\hline Impedance drop per point, $\Omega^{*}$ & $10.13 \pm 1.624$ & $6.57 \pm 1.012$ & $<0.001$ \\
\hline First-pass PVI, n (\%) & $87(87)$ & $72(72)$ & $<0.01$ \\
\hline Reconnection after 20 min, n (\%) & $22(11)$ & $46(23)$ & $<0.01$ \\
\hline Groin hematoma, n .(\%) & 1 & 1 & 1 \\
\hline Tamponade, n (\%) & 0 & 0 & 1 \\
\hline Peri-procedural stroke, n (\%) & 0 & 0 & 1 \\
\hline Esophageal fistula, n (\%) & 0 & 0 & 1 \\
\hline Sinus rhythm at $12 \mathrm{mo}, \mathrm{n}(\%)$ & $46(92)$ & $42(84)$ & 0.22 \\
\hline
\end{tabular}




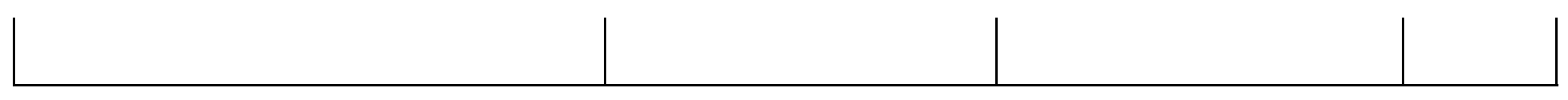

Values are mean \pm SD or $\mathrm{n}(\%)$

\section{Figures}

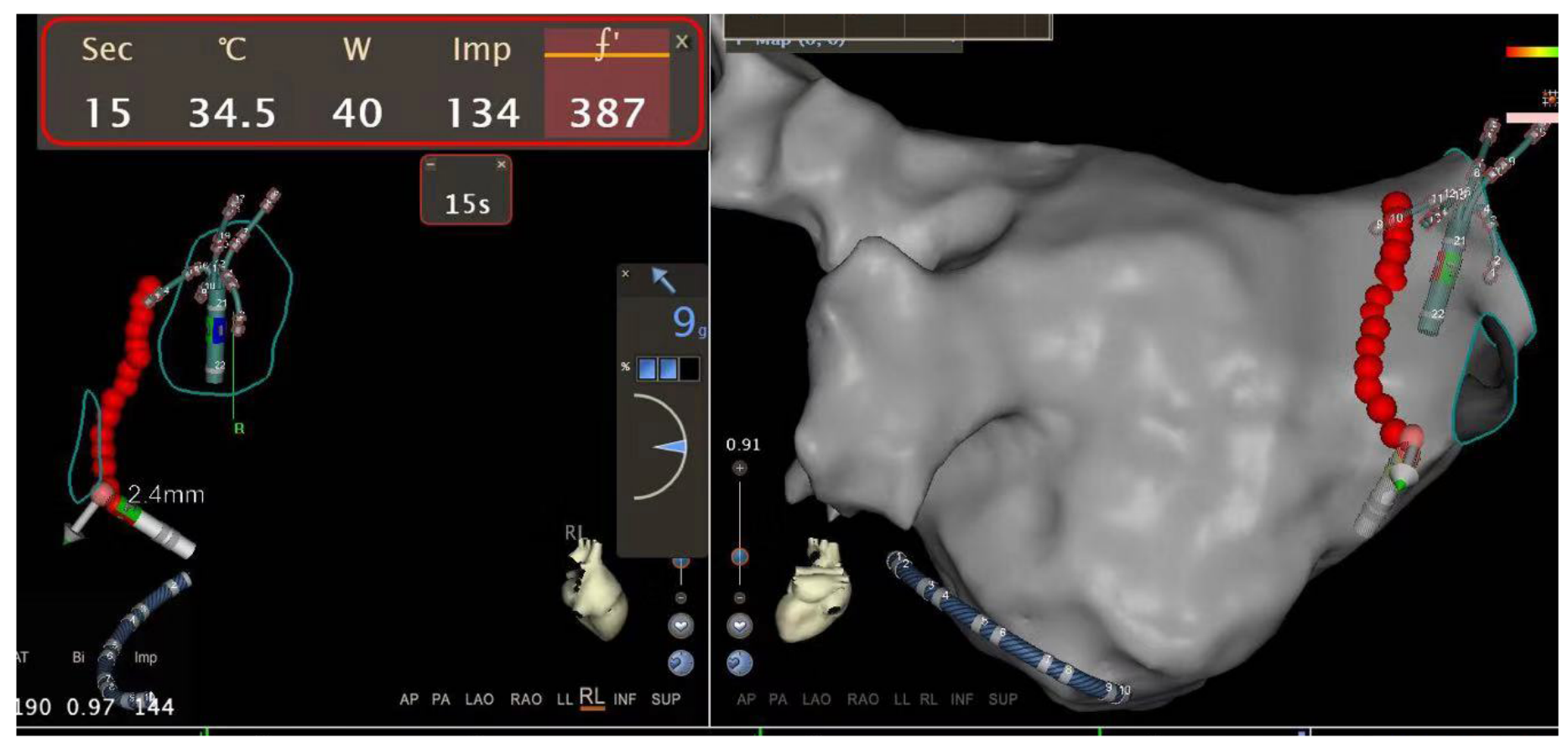

Figure 1

Al-guided ablation injury. VISITAGs placement with Distance Measure Tool. 
A

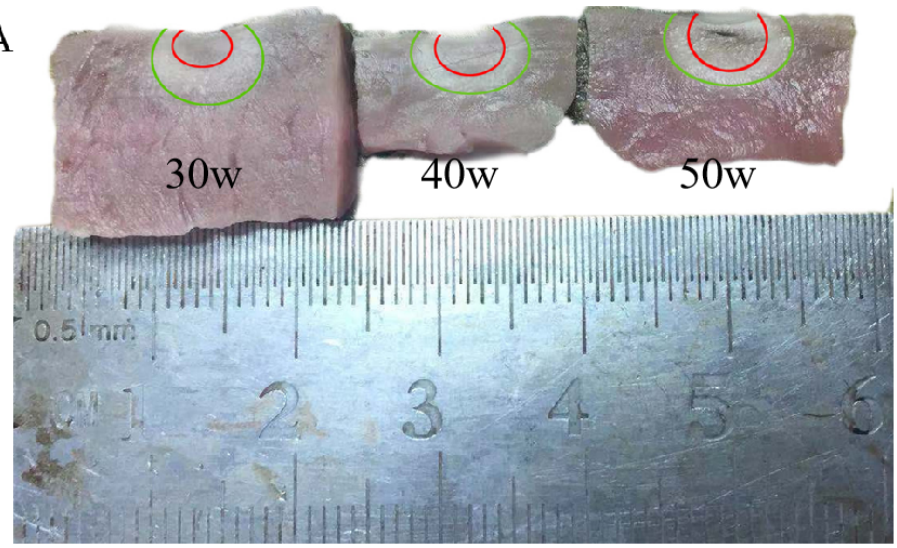

C

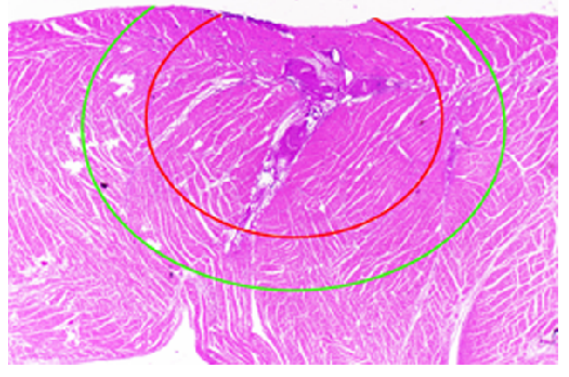

B
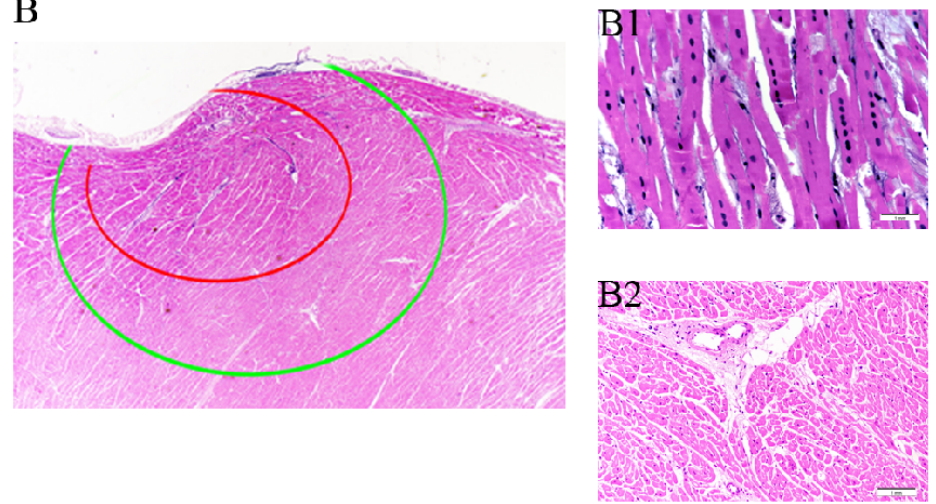

D

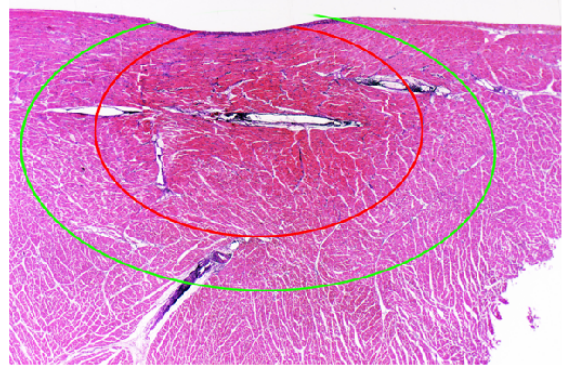

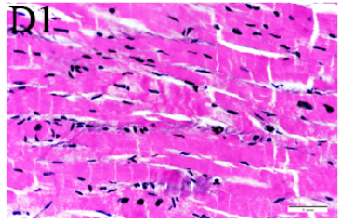

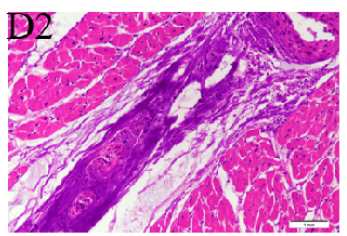

\section{Figure 2}

Ventricular lesions obtained with constant Al of 500 and with 50W, 40W or 30W of power output. A. By visual inspection, increasing power was associated with larger lesion maximum diameter(green line) and deeper tissue necrosis(red line), with boundaries of tissue lesion and necrosis becoming clearer. B-D. Lesions (green line) and necrosis (red line) generated with 30W, 40W and 50W were examined under 20x amplification; under 400x magnification at $1 \mathrm{~mm}$ from the ablation catheter tip in panels B1 (mainly basophilic changes of connective tissue with least myocardial cell changes and nuclear pyknosis), C1 (small number of myocardial cells with fuzzy sarcoplasm, no horizontal stripes and nuclear pyknosis) and D1 (largest number of affected myocardial cells); and under 200x magnification at 3mm from the ablation catheter tip in panels B2 (no basophilic changes of fibrous connective tissue), C2 (basophilic changes only around cells) and D2 (basophilic changes around the blood vessels and cells). 


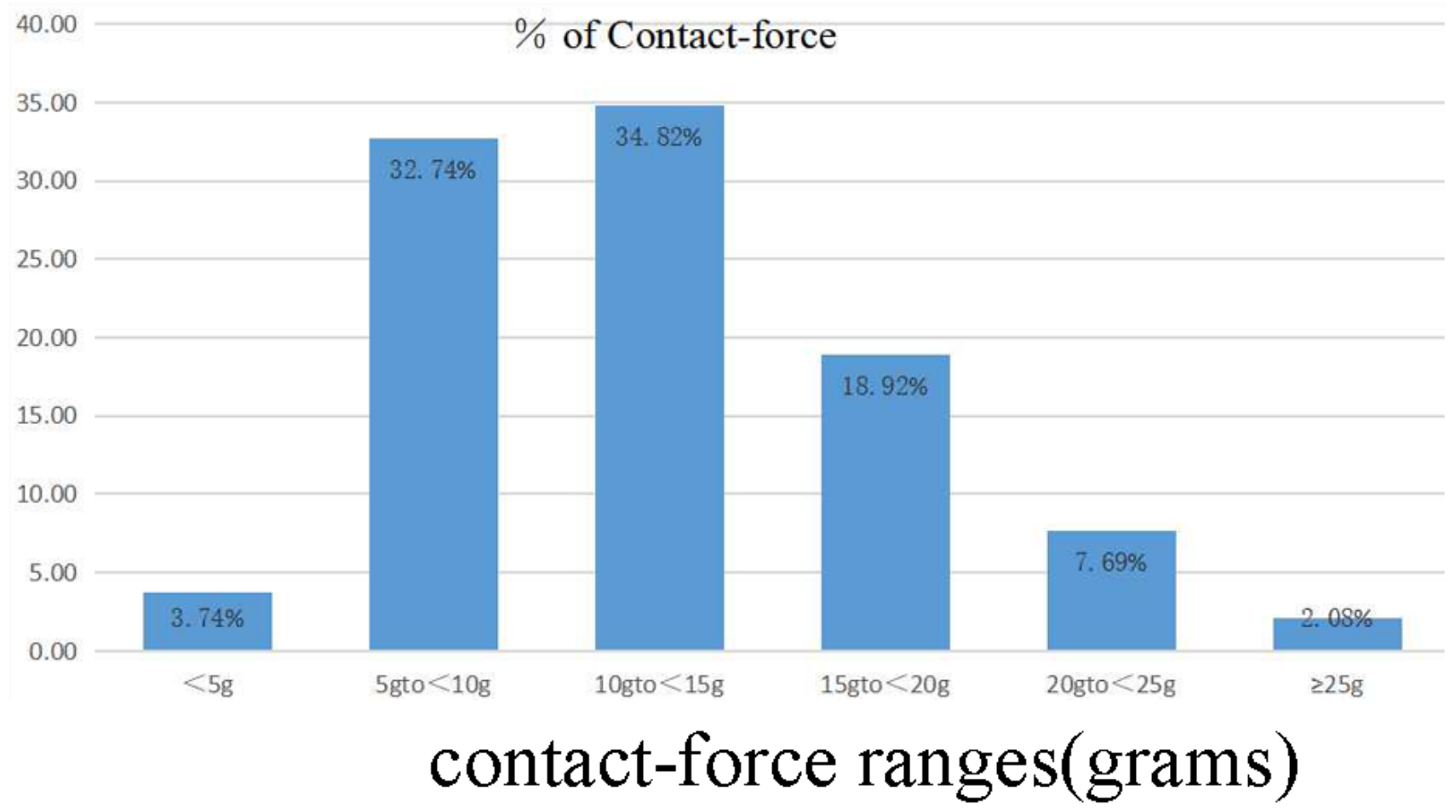

Figure 3

Percentage of total number of RF lesions by average CF ranges.

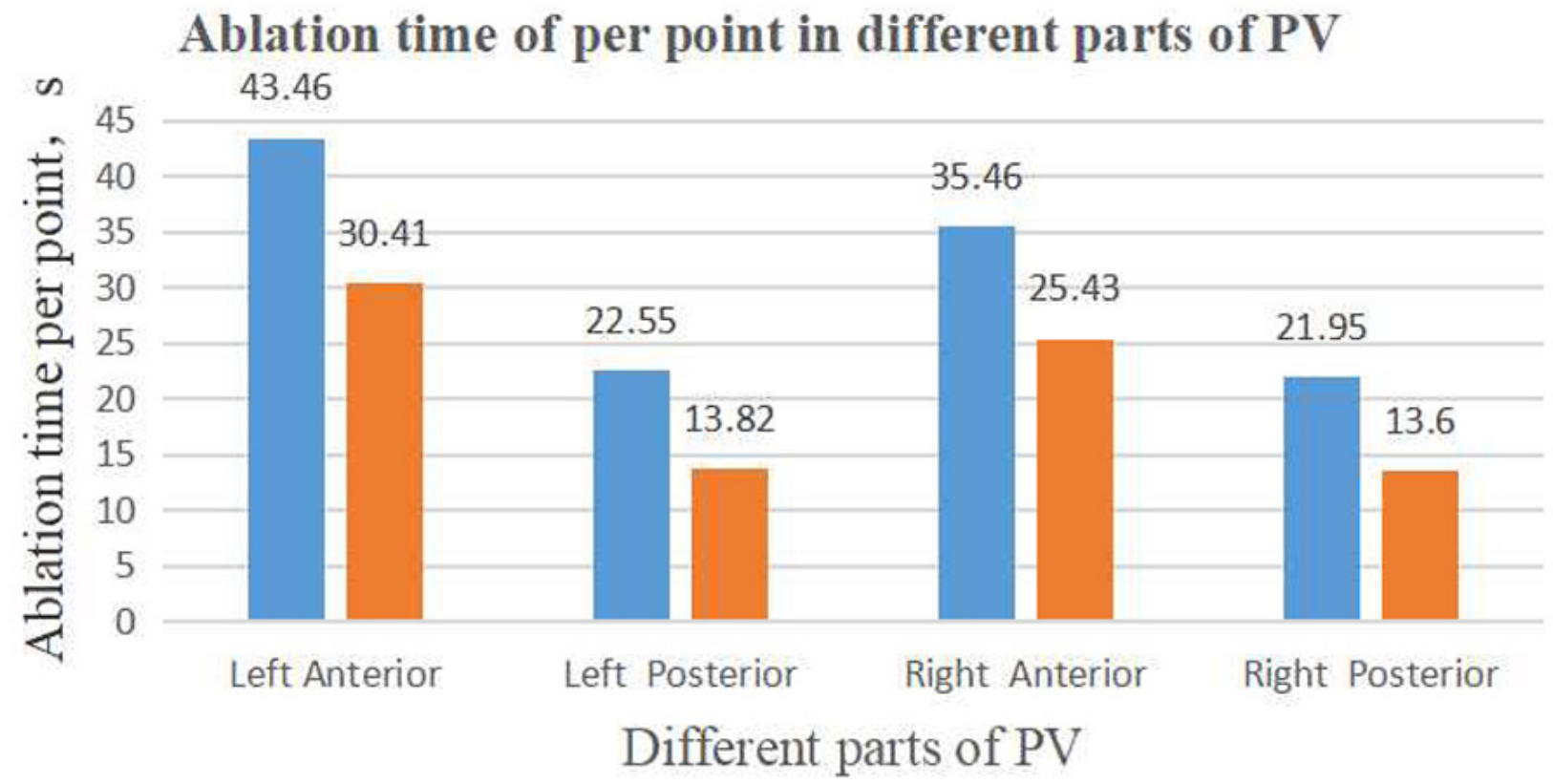

Figure 4 
Ablation time per point throughout PV.

\section{Energy delivery of per point in different parts of PV}

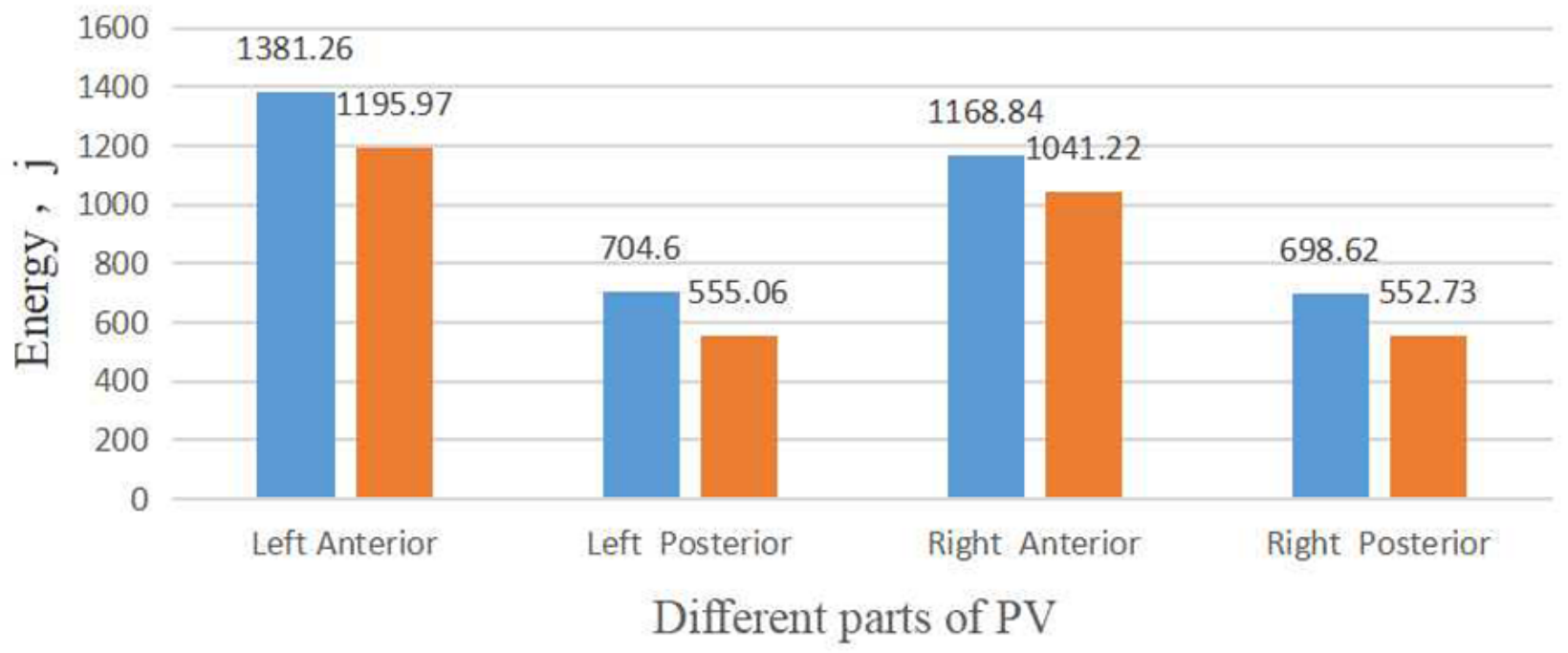

$30 \mathrm{w}=40 \mathrm{w}$

\section{Figure 5}

Energy delivery per point throughout PV.

$\%$ of Contact-force in different parts of PV

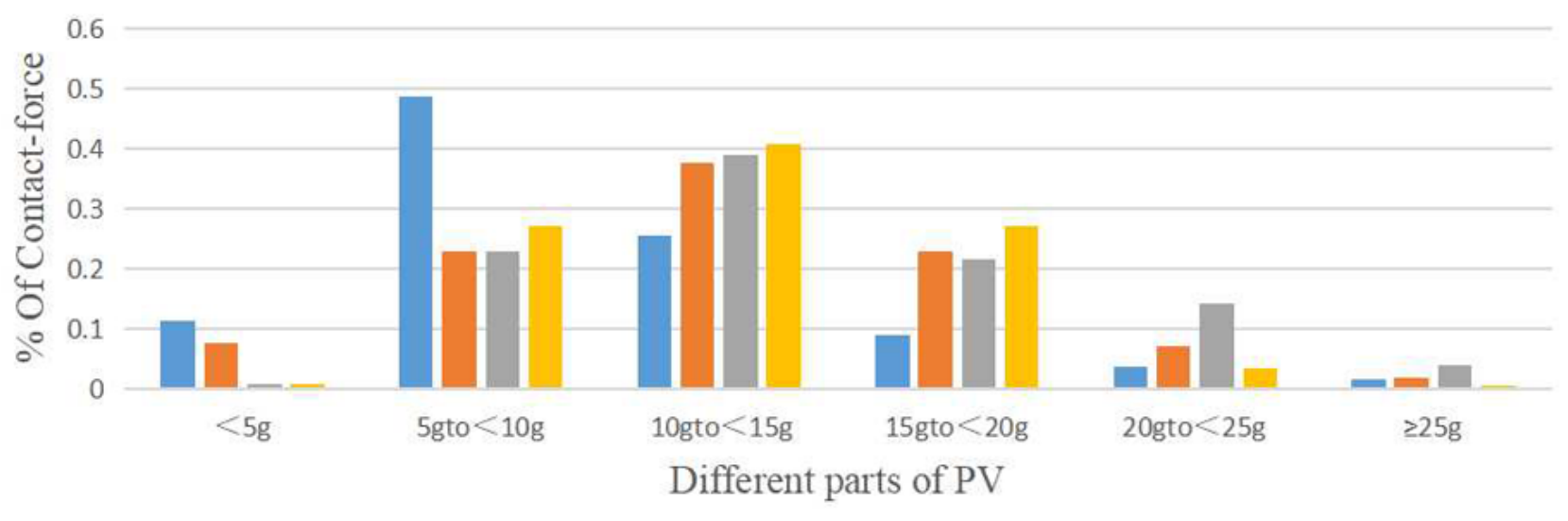

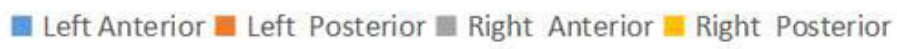


Figure 6

The distribution of Contact-force in different parts of PV.

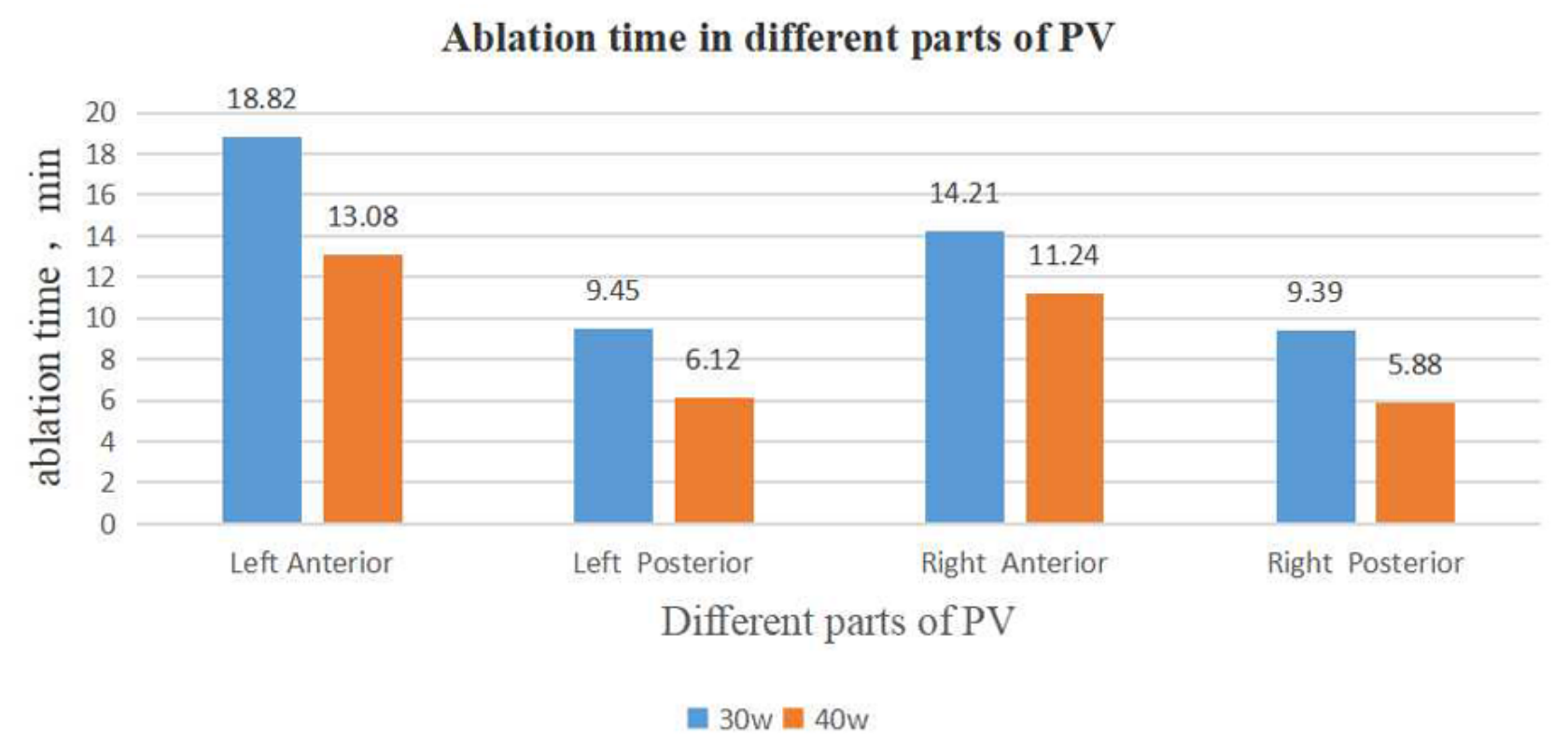

Figure 7

Ablation time throughout PV.

\section{Supplementary Files}

This is a list of supplementary files associated with this preprint. Click to download.

- CONSORT2010Checklist.docx 